
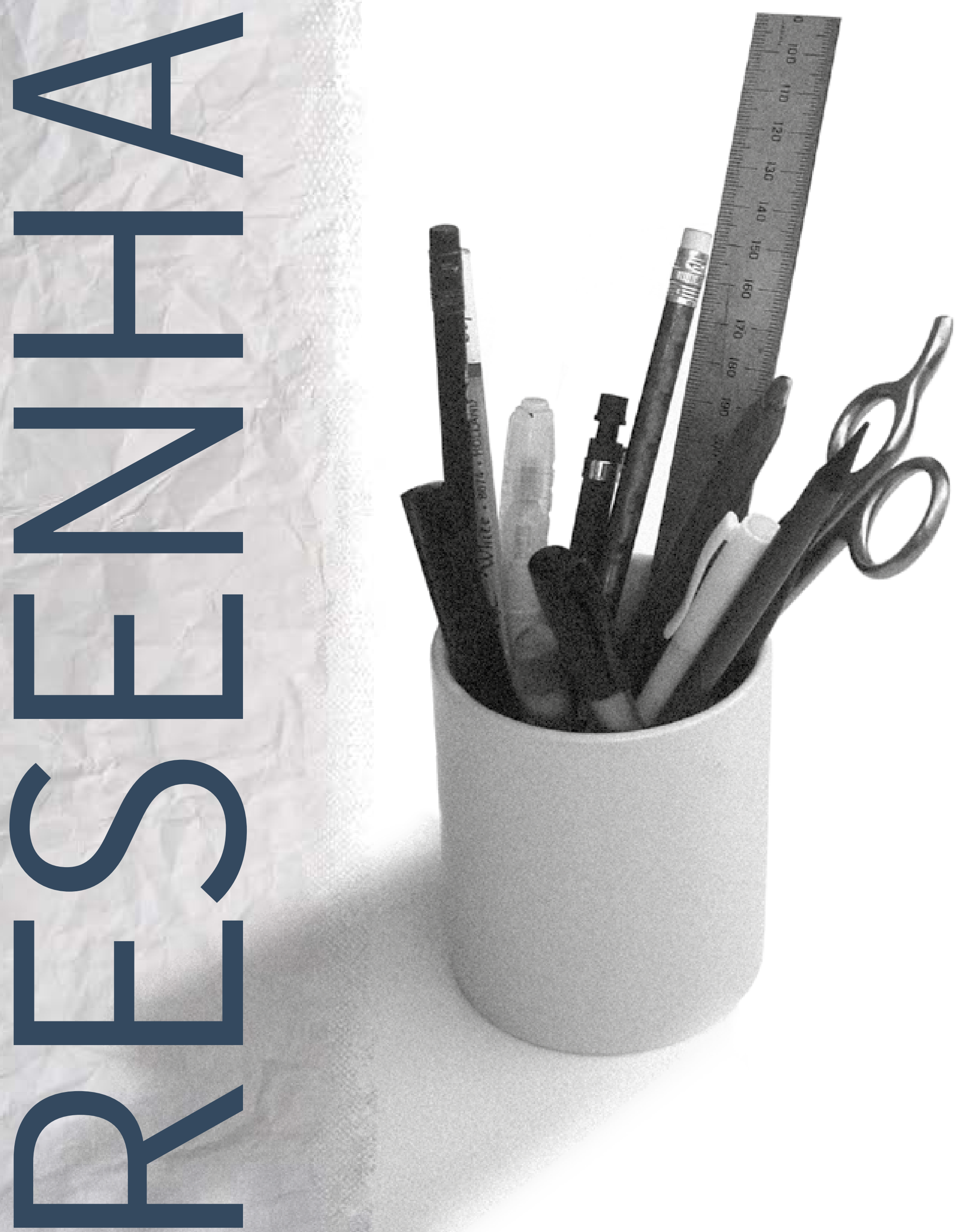


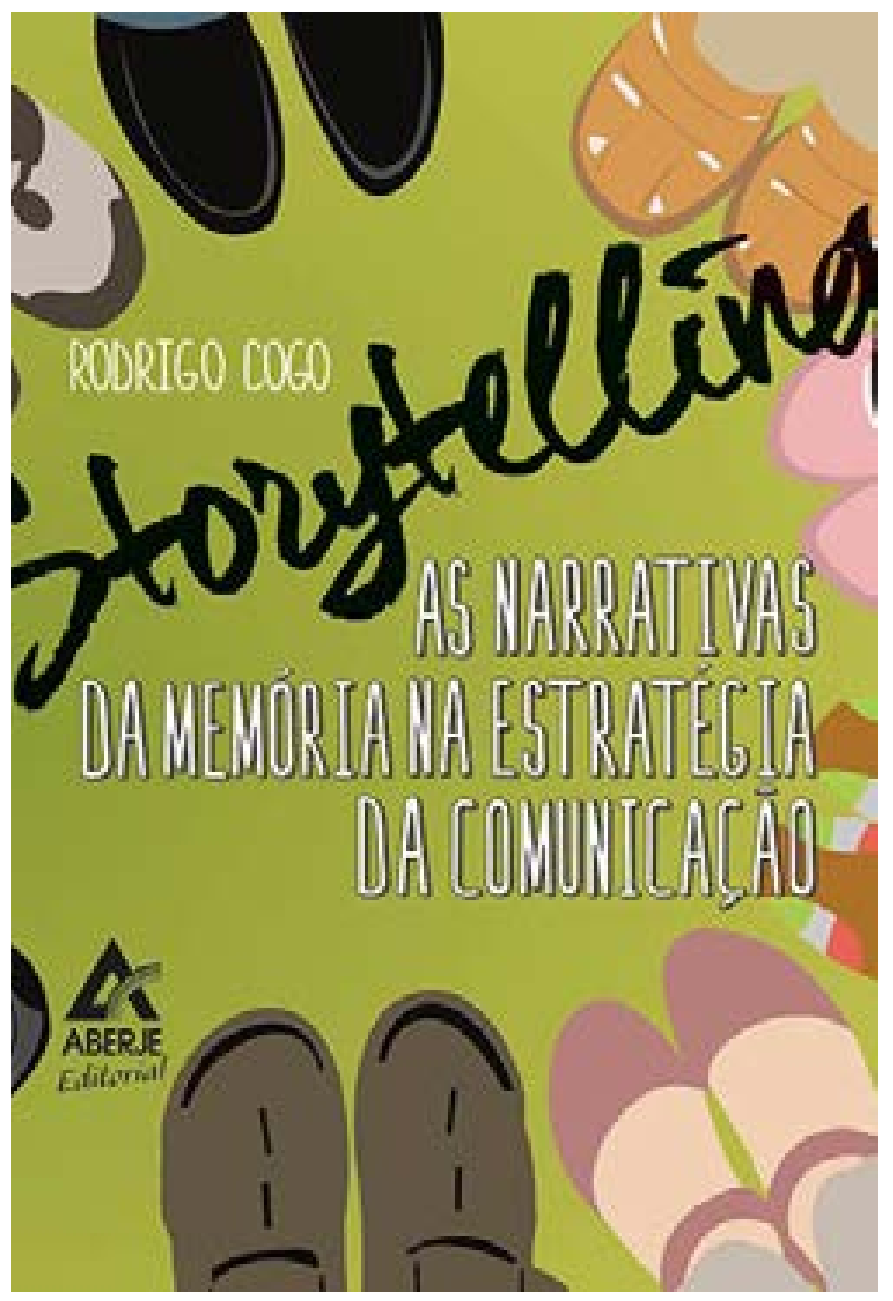

Rodrigo Silveira Cogo

Storytelling: as narrativas da memória na estratégia da comunicação

São Paulo, SP

Aberje Editorial, 2016

177 páginas

Resenhado por

\section{Emiliana Pomarico Ribeiro}

- Doutoranda em Ciências da Comunicação no Programa de Pós-Graduação da Escola de Comunicações e Artes da Universidade de São Paulo (ECA-USP)

- Mestre em Ciências da Comunicação pela ECA-USP

- Graduada em Relações Públicas pela ECA-USP

- Tecnóloga em Produção Audiovisual pela Universidade Paulista (Unip)

- Integrante do Grupo de Estudos de Novas Narrativas (Genn) da ECA-USP

- E-mail:emi.pomarico@gmail.com 


\title{
Uma nova narrativa como voz de um novo tempo
}

\author{
A new narrative as the voice of new times
}

\section{Una nueva narrativa como voz de un nuevo tiempo}

$\mathrm{E}$

m seu recém-lançado livro, intitulado Storytelling: as narrativas da memória na estratégia da comunicação, Rodrigo

Cogo reflete, a partir da interpretação de conceitos e opiniões de mais de duzentos autores, a constatação de que a comunicação empresarial passa por uma crise essencial, à medida que se expressa, principalmente, por uma narrativa mecânica, interesseira, padronizada e descompromissada, sem espaço para memórias, experiências profundas, mitos, histórias e afetos nas organizações. 0 raciocínio parece ainda mais valoroso se compreendermos a trajetória do autor: tem sólida carreira em comunicação organizacional iniciada em uma multinacional norte-americana, passou pela área de pesquisa qualitativa em reconhecido instituto de avaliação da comunicação paulista, integra a equipe da Associação Brasileira de Comunicação Empresarial (Aberje) e não deixou de lado seu aperfeiçoamento em especialização e mestrado. Nesse caminho, somou diversas reflexões sobre práticas empresariais e conseguiu propor renovações a partir da teoria.

Baseado em sua dissertação de mestrado - defendida com louvor em 2012 na Escola de Comunicações e Artes da Universidade de São Paulo (ECA-USP), orientado pelo professor livre-docente Paulo Nassar, pioneiro na pesquisa brasileira e internacional da interface entre relações públicas e o campo das narrativas baseadas nas memórias e nas experiências, Rodrigo Cogo apresenta de forma brilhante e clara seus conhecimentos sobre o formato narrativo do storytelling, propondo análises e esquemas que auxiliam o entendimento e a aplicação desse novo paradigma narrativo em estratégias de comunicação que prezam pela abertura das afetividades, em uma linguagem de encontro, compreensão, qualidade e reencantamento das relações, geridas em ambientes humanizados. 0 trabalho de mestrado que inspirou a publicação desse livro encontrase disponível no Banco de Teses e Dissertações da Universidade de São Paulo no link < http://www.teses.usp.br/teses/ disponiveis/27/27154/tde-05122012-171130/pt-br.php>.

Na obra, Cogo retrata a necessidade de se trabalhar com as memórias que, quando narradas, podem se transformar em histórias. Histórias estas capazes de sensibilizar, envolver, trazer identificações e confianças, chamar a atenção e gerar sentidos e significados para as mensagens transmitidas, mesmo em um contexto digital, fluido, randômico, racional 
e exposto, no qual imperam as saturações com excessos informacionais e o consequente déficit de atenção - conceito explorado pelo professor Thomas Davenport e pelo pesquisador John Beck, com o qual eles afirmam que, por haver informação e conhecimento em abundância, há proporcionalmente um decréscimo na oferta da atenção humana.

Essas ideias ficam evidentes logo no primeiro capítulo, "A confiança na comunicação sob o impacto do multiprotagonismo", o qual traz importantes reflexões sobre o cenário instável em que vivemos: pós-moderno, digital e polifônico, em que se encontram seres multitarefas ou, como conceituado pelo antropólogo e professor Máximo Canevacci, "multivíduos". Tratase de sujeitos possuidores de uma identidade fluida e pluralizada, exercendo diversos papéis sociais. Críticos e propositivos, rejeitam padronizações, estão hiperconectados e são bombardeados por estímulos externos de mensagens de todas as origens.

Sobre essas ideias é construída a reflexão de como então poderiam ser realizadas estratégias de comunicação efetivas para essa nova lógica e esses novos sujeitos. Com essa dúvida exposta, a angústia do comunicador leitor é acalmada ao ser levado a refletir, pela voz do autor, que "o depoimento de vida que nasce no âmbito dos públicos, das redes sociais ou da sociedade tem um alto valor para a formação da confiança na empresa ou instituição, porque é percebido pelos receptores como algo distante dos interesses das organizações e compatível com os interesses dos receptores" (p. 54). Isso significa que humanizar as relações e as comunicações é o panorama essencial para o storytelling, assim como para a participação, a manifestação das subjetividades, das sensibilidades e da efetiva diversidade da escuta.

O segundo capítulo, "História e memória organizacionais como lastro comunicativo", discorre sobre o passado, o presente e o futuro e trata da relevância da responsabilidade histórica como ativo reputacional de uma organização. É neste ponto que Cogo nos alerta para o surgimento de uma "moda da memória" como reação à tecnologia, ao consumismo, ao imediatismo, à superficialidade e à descartabilidade das relações, dialogando com autores que diferenciam os conceitos de história e de memória, como Jacques Le Goff, Paulo Nassar, Suzana Ribeiro, Marieta de Moraes Ferreira e Ecléa Bosi. Para eles, um ponto em comum é que a memória é pautada em emoções e representações, lembrada de forma profunda e ativa, latente e penetrante, oculta e invasora, à luz das experiências subsequentes e das necessidades do presente. Essa memória, quando narrada, pode se transformar em história e em conhecimento, legitimando as mensagens da organização, consolidando culturas, construindo marcas e identidades e gerando confiança, através do encantamento do espírito e do enriquecimento das experiências, contribuindo para a própria perpetuação da organização.

No terceiro e último do livro, "A elaboração discursiva da memória organizacional: o storytelling como paradigma narrativo", há um precioso levantamento, sobretudo de autores internacionais, sobre o conceito de storytelling, apontando que, nos últimos vinte anos, temas como empatia, preocupação e compromisso, interação interpessoal, caráter pessoal e personalidade ganharam maiores proporções, assim como a criação de mitos, ritos, rituais, heróis organizacionais e todo um universo simbólico que rodeia os processos do paradigma narrativo. Ao final, o autor sugere uma matriz estruturante de elementos constitutivos do storytelling, a qual já teve destaque no número 20 da revista Organicom. De acordo com seus estudos, os elementos constitutivos do storytelling, sobretudo em formato audiovisual, seriam dez: tom confessional, narrativa em primeira pessoa, relato lacunar, fala lateralizada, repertório coloquial, exposição de vulnerabilidade, proposta inspiracional, universalidade temática, jogo de suspense e curiosidade e vigor emocional. 0 autor deixa uma abertura para que futuros pesquisadores do tema possam discutir e aprofundar o raciocínio acerca desses elementos, já que é uma proposta inovadora e que tenta oferecer uma régua em nome da qualidade dos trabalhos no mercado neste assunto. A matriz é estimulante e já foi, inclusive, testada pelo autor em monografia de especialização do MBA em Gestão da Comunicação Empresarial, da Aberje, podendo certamente ser o ponto de partida para outros voos. 
Rodrigo Cogo aposta, em toda a obra, mas especialmente nas conclusões, neste paradigma narrativo como a voz de um novo tempo: conversacional, inclusivo, colaborativo, afetivo, duradouro e memorável. E acaba por elaborar sua própria definição de storytelling organizacional como sendo: "uma lógica de estruturação do pensamento e um formato de organização e difusão de narrativa, por suportes impresso, audiovisual ou presencial, baseados nas experiências de vida próprias ou absorvidas de um interagente - ou ainda inventadas, derivando relatos envolventes e memoráveis". É um trabalho pioneiro sobre este enfoque no Brasil, reunindo grandes nomes da comunicação, da sociologia, da psicologia e da história e trazendo um novo pensamento para os territórios das relações públicas e da comunicação em organizações. 